Gut, 1982, 23, 71-74

\title{
Experimental infection of lambs with Cryptosporidium isolated from a human patient with diarrhoea
}

\author{
S TZIPORI, * K W ANGUS, I CAMPBELL, AND E W GRAY \\ From the Moredun Research Institute, Edinburgh
}

SUMmARY An inoculum containing Cryptosporidium oocysts obtained from an adult human patient with acute transient diarrhoea induced enteritis in two newborn specific pathogen free lambs. Three days after inoculation the lambs became depressed and diarrhoeic, their milk intake was reduced, and Cryptosporidium oocysts were detected in their faeces. Mucosal changes observed in the small intestine of one infected lamb were consistent with but less severe than those induced experimentally in lambs by cryptosporidia isolated from calves and lambs.

Cryptosporidiosis, an infection of the intestinal mucosa by a protozoan of the enteric coccidia group, has been recognised in animals since the beginning of the century. ${ }^{1}$ However, an association of Cryptosporidium with disease was circumstantial until recently when its potential as an enteropathogen was recognised. ${ }^{2-6}$

Cryptosporidium was first described in man in $1976^{7}$ and a total of nine cases has since been reported, ${ }^{8-13}$ five in immunologically-compromised patients, ${ }^{8-12}$ two of whom died. ${ }^{11}{ }^{12}$ Infection was confirmed by intestinal biopsies except for three cases where oocyst excretion in the faeces was used for diagnosis.

In a previous communication ${ }^{13}$ we described the clinical features of a case of acute transient diarrhoea in an adult human patient with Cryptosporidium infection. Cryptosporidium oocysts in the patient's faeces infected day-old suckling specific pathogen free (SPF) mice and two newborn SPF lambs. In this report we describe the clinical manifestations and pathological findings in the infected lambs.

\section{Methods}

INOCULATION OF EXPERIMENTAL ANIMALS Three newborn SPF lambs were maintained separately in plastic isolators and were offered reconstituted evaporated cow's milk three times

*Present address: Attwood, Veterinary Research Laboratory, Mickleham Road, Westmeadows, Victoria 3047, Australia.

Received for publication 17 August 1981 daily. Two of the lambs (1 and 2) were given $5 \mathrm{ml}$ orally of homogenates of the patient's faeces $(20 \% \mathrm{v} / \mathrm{v}$ in PBS) containing Cryptosporidium oocysts. The inoculum contained no salmonellae as determined by culture on MacConkey agar after enrichment in selenite broth, and direct EM examination failed to detect known enteric viral pathogens. Lamb 3 was maintained as an uninoculated control. Clinical appraisal of the lambs was carried out twice daily, their milk intake was recorded (Fig. 1), and rectal swabs were examined daily by EM for the presence of enteric viruses. Excretion of Cryptosporidium oocysts was demonstrated by Giemsa staining of faecal smears.

NECROPSY AND HISTOLOGY

Lamb 1 was killed four days after inoculation, while lamb 2 and the control lamb 3, were killed three days later. The lambs were anaesthetised and representative samples were collected from the abomasum and five equally spaced sites along the small intestine, together with one each from the spiral colon and caecum. One portion of each sample was fixed in $10 \%$ formol saline and processed for histology. Blocks of mucosa, approximately $2 \times 1 \times 1 \mathrm{~mm}$, were fixed in $3 \%$ glutaraldehyde in phosphate buffer and processed for transmission electron microscopy (TEM). The contents of the small and large intestines were examined for the presence of enteropathogens as described above. Portions of intestine from the jejunum and upper and lower ileum were taken for the measurement of levels of lactase and sucrase activity. ${ }^{14}$ Paraffin 


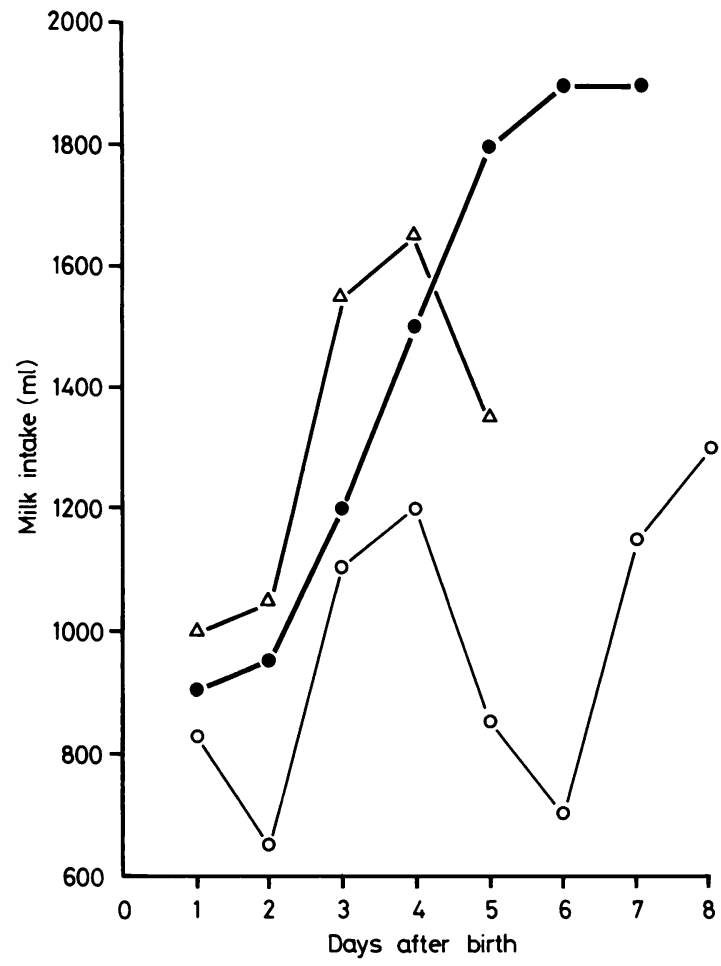

Fig. 1 Milk consumption of lambs experimentally inoculated with Cryptosporidium in human stool homogenate. $\triangle$ Lamb 1. OLamb 2. OControl lamb. sections $6 \mu \mathrm{m}$ thick were stained by Mayer's haematoxylin and eosin, phloxin tartrazine, and by Giemsa's method.

\section{Results}

CLINICAL AND MICROBIOLOGICAL FINDINGS Three days after inoculation, lambs 1 and 2 became slightly depressed, and diarrhoea was apparent in lamb 1. Cryptosporidium oocysts were detected in Giemsa stained faecal smears from both lambs. Lamb 1 was killed 18 hours after the onset of clinical illness. Lamb 2 had intermittent diarrhoea, with reduction in milk intake (Fig. 1) and was killed four days after the onset of illness when it was apparently beginning to recover. Oocysts were detected in the faeces of this lamb right up to the time of death. No oocysts or viral enteropathogens were detected in the faeces of the control lamb 3 throughout the entire observation period.

\section{HISTOLOGICAL FINDINGS}

In lamb 1, killed four days post-inoculation, cryptosporidia were found in the brush borders of villous enterocytes throughout the entire small intestine (Fig. 2) except for the most proximal site. Infection was most extensive in the ileum. The large intestine was not infected. Changes included areas of stunted villi, particularly those overlying Peyer's patch areas of the ileum, and small foci of fused villi in the posterior jejunum and ileum. Fused or

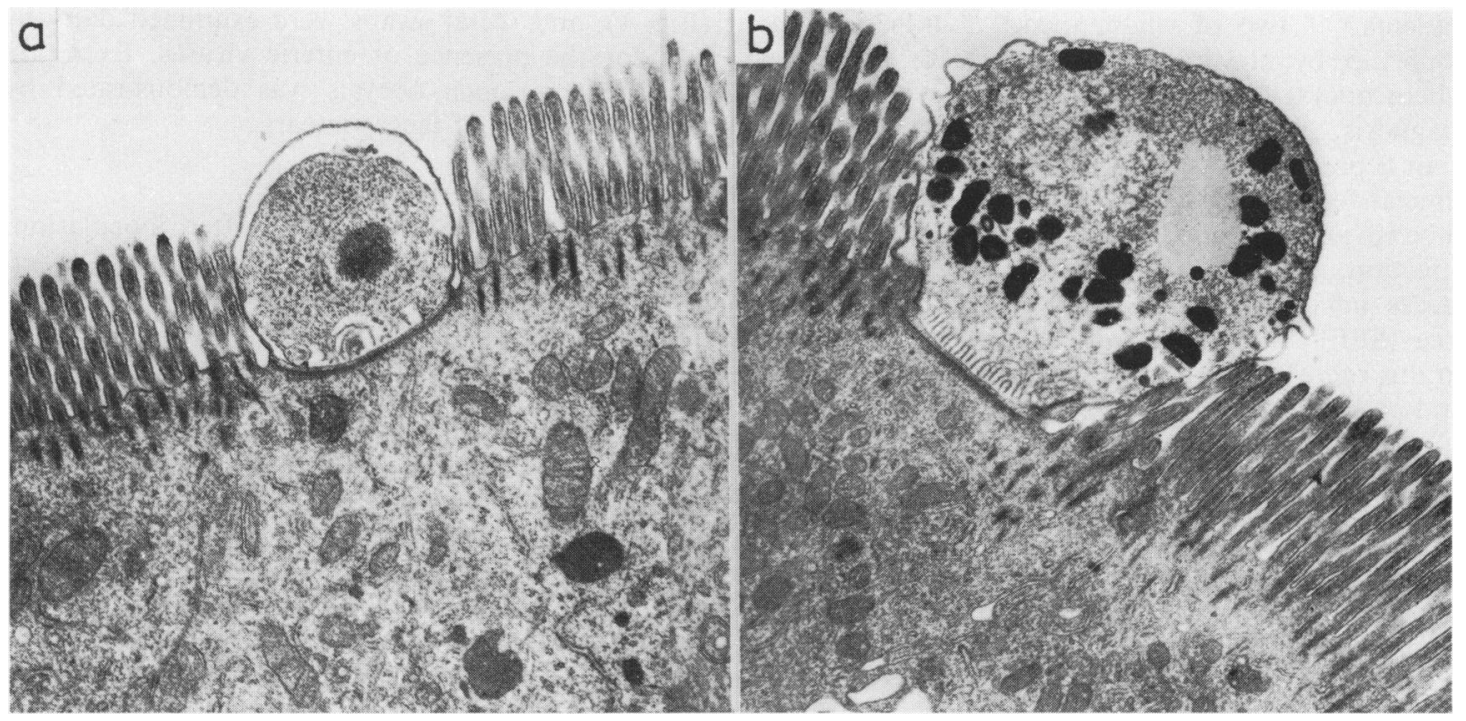

Fig. 2 Trophozoite (a) and macrogamete (b) of Cryptosporidium in lamb ileal enterocytes. Lead citrate, $\times 16000$ (original magnification). 
stunted villi were clad in cuboidal epithelial cells but long slender villi, even when quite heavily infected by the parasite, were covered in columnar cells (Fig. 3). The lamina propria of the distal small intestine contained substantial infiltrates of neutrophils and a few macrophages, and some crypts contained dead leucocytes. Many mucosal capillaries, particularly in Peyer's patch areas, contained plugs of neutrophils but the lymphoid tissue of the Peyer's patches resembled that of normal SPF lambs. The caecal and colonic mucosa was infiltrated by a few neutrophils but was otherwise unaffected.

In the second lamb, killed at seven days postinoculation, rather sparse numbers of crypto-

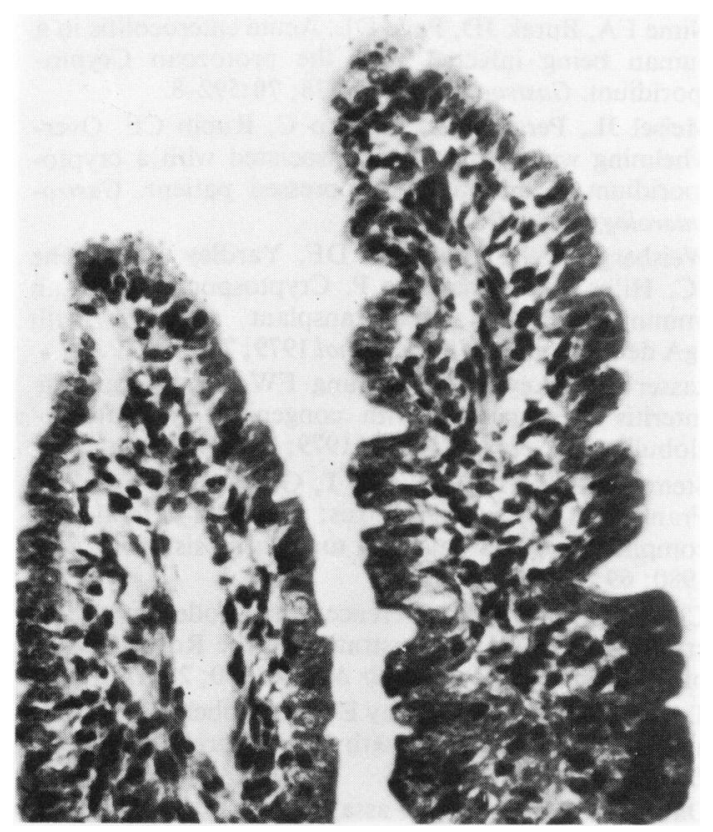

Fig. 3 Cryptosporidium infecting lamb jejunal villi. Note that the villi are clad in columnar epithelial cells. Giemsa, $\times 370$ (original magnification). sporidia were found infecting the posterior small intestine and caecum. Apart from slight infiltration of mononuclear cells in the caecal mucosa, no significant changes were found in lamb 2 .

No infection or pathological changes were found in the abomasa of either of the lambs.

\section{ENZYMOLOGY RESULTS}

The Table shows that the level of activity of lactase in the two inoculated lambs was markedly suppressed in the upper and lower ileum, while sucrase activity could not be detected at any of the three intestinal sites, compared with the control.

\section{Discussion}

The results show that Cryptosporidium oocysts in faeces obtained from an adult human patient suffering from acute, but transient, diarrhoea infected and may have caused enteritis in newborn SPF lambs. The depressed levels of disaccharidase activity probably reflect a degree of mucosal damage which would in turn affect digestion and absorption. Experimental cryptosporidiosis in lambs caused by cryptosporidia obtained from several different animal species has recently been reported 45 and the present findings, which constitute the first experimental infections induced by a human Cryptosporidium isolate, are similar. Cryptosporidium isolated from calves, however, induced fatal disease in lambs associated with extensive mucosal damage. ${ }^{18}$ The difference in severity between the calf and human isolates could be due either to differences in the nature of the inoculum-that is, quantity and degree of viability of oocysts, neither of which was determined-or to a fundamental difference between isolates from two different species. The latter appears less likely as the human, calf, deer, and lamb isolates all induced diarrhoea with clinical illness in lambs and subclinical infection in laboratory animals. ${ }^{4} 51518$

Subsequent passage in suck ling SPF mice of oocysts obtained from the two lambs described in this

Table Lactase and sucrase levels (mol/min/g wet weight) at different sites of intestine of two lambs (land 2) inoculated with Cryptosporidium and a control lamb (3)

\begin{tabular}{|c|c|c|c|c|c|c|}
\hline \multirow[t]{2}{*}{$L a m b$} & \multicolumn{2}{|c|}{ Upper jejunum } & \multicolumn{2}{|c|}{ Upper ileum } & \multicolumn{2}{|c|}{ Lower ileum } \\
\hline & Lactase & Sucrase & Lactase & Sucrase & Lactase & Sucrase \\
\hline $\begin{array}{l}1 \\
2 \\
3 \\
\text { (Control) }\end{array}$ & $\begin{array}{l}5 \cdot 62 \\
3 \cdot 51 \\
5 \cdot 10\end{array}$ & $\begin{array}{l}0 * \\
0 \\
0.55\end{array}$ & $\begin{array}{r}1.69 \\
0.93 \\
12.36\end{array}$ & $\begin{array}{l}0 * \\
0 \\
0 \cdot 50\end{array}$ & $\begin{array}{l}0.31 \\
0.26 \\
1.69\end{array}$ & $\begin{array}{l}0 . \\
0 \\
0.31\end{array}$ \\
\hline
\end{tabular}

*Below detectable levels. 
experiment (S Tzipori and I Campbell, unpublished data) offers further support for the proposal that Cryptosporidium, including the human isolate, lacks host specificity and should be regarded as a potential zoonosis. ${ }^{15}$

There is little doubt that these organisms are widespread in vertebrates. A recent limited study has shown that more than $90 \%$ of 225 sera obtained from 10 different animal species and man had antibody against the calf cryptosporidium, as measured by the indirect immunofluorescence test. ${ }^{16}$ Although endogenous stages of the parasite appear to carry surface determinants capable of binding to antibody present in convalescent lamb serum (DR Snodgrass, personal communication), the immunology of Cryptosporidium infections has not been investigated and the role of humoral antibody in the development of resistance is unknown. However, the readiness with which certain strains of laboratory mouse can be subclinically infected with different isolates of the parasite from various animal species (D Sherwood and K W Angus, unpublished data) should provide the impetus for immunological studies.

Sequential passage of the organism in mice is a useful method for maintaining the infectivity of isolates as attempted long-term storage of infective inocula has so far been unsuccessful. Another difficulty relates to the quantification of infectious doses. Although oocyst numbers can be determined, ${ }^{17}$ assessment of their viability still remains a problem. Titration in SPF mice of inocula containing unknown numbers of oocysts may prove to be a practical method of quantification (D Sherwood, personal communication).

Experimental inoculation of SPF lambs with other human isolates is necessary to establish whether the lamb is a suitable experimental animal for development of therapeutic measures against this potentially important disease of man and animals.

The authors are grateful for the help of the Institute's photography section, and that of Mrs Margaret Gordon of the Western General Hospital, Edinburgh, for carrying out the assay on disaccharidases.

\section{References}

${ }^{1}$ Tyzzer GC. A sporozoan found in the peptic glands of the common mouse. Proc Soc Exp Biol Med 1907; $540: 12-3$.
2Pohlenz J, Moon HW, Cheville NF, Bemrick WJ Cryptosporidiosis as a probable factor in neonatal diarrhoea of calves. J Am Vet Med Assoc 1978; 172: 452-7.

${ }^{3}$ Snodgrass DR, Angus KW, Gray EW, Keir WA, Clerihew LW. Cryptosporidia associated with rotavirus and an Escherichia coli in an outbreak of calf scour. Vet Rec 1980; 106:458-9.

${ }^{4}$ Tzipori S, Campbell I, Sherwood D, Snodgrass DR, Whitelaw A. An outbreak of calf diarrhoea attributed to cryptosporidial infection. Vet Rec $1980 ; 107: 579-80$.

${ }^{5}$ Tzipori S, Angus KW, Campbell I, Sherwood D. Diarrhea in young red deer associated with Cryptosporidium infection. $J$ Infect Dis $1981 ; 144: 170-5$.

${ }^{6}$ Tzipori S, Angus KW, Campbell I, Clerihew LW. Diarrhea due to Cryptosporidium infection in artificially reared lambs. J Clin Microbiol 1981; 14: $100-5$.

${ }^{7}$ Nime FA, Burek JD, Page DL. Acute enterocolitis in a human being infected with the protozoan Cryptosporidium. Gastroenterology 1976; 70:592-8.

${ }^{8}$ Meisel JL, Perera DR, Meligro C, Rubin CE. Overwhelming watery diarrhoea associated with a cryptosporidium in an immunosuppressed patient. Gastroenterology 1976; 70:1156-60.

${ }^{9}$ Weisberger WR, Hutcheon DF, Yardley JH, Roche JC, Hillis WD, Charache P. Cryptosporidiosis in an immunosuppressed renal-transplant recipient with IgA deficiency. Am J Clin Pathol 1979; 72:473-8.

${ }^{10}$ Lasser KH, Lewin KJ, Ryning FW. Cryptosporidia enteritis in a patient with congenital hypogammaglobulinemia. Human Pathol 1979; 10:234-40.

${ }^{11}$ Stemmermann GN, Hayashi T, Glober GA, Oishi N, Frankel RI. Cryptosporidiosis: report of a fatal case complicated by disseminated toxoplasmosis. Am J Med 1980; 69:637-42.

${ }^{12}$ Clinicopathological conference. Immunodeficiency and cryptosporidiosis: demonstration at the Royal College of Physicians of London. Br Med J 1980; 281 :1:123-7.

${ }^{13}$ Tzipori S, Angus KW, Gray EW, Campbell I. Vomiting and diarrhoea associated with cryptosporidial infection. Engl J Med 1980; 303:818.

${ }^{14}$ Dahlqvist A. Method for assay of intestinal disaccharidases. Anal Biochem 1964; 1:18-25.

${ }^{15}$ Tzipori S, Angus KW, Campbell I, Gray EW. Cryptosporidium: evidence for a single-species genus. Infect Immunol 1980; 30:884-6.

${ }^{16}$ Tzipori S, Campbell I. Prevalence of Cryptosporidium antibodies in ten species of animal. J Clin Microbiol 1981 J Clin Microbiol 1981; 14:455-6.

${ }^{17}$ Iseki M. Cryptosporidium felis sp n (protozoa: Emeriorina) from the domestic cat. Jpn J Parasitol 1979; 28:285-307.

${ }^{18}$ Tzipori S, Angus KW, Gray EW, Campbell I, Allan F Diarrhea in lambs experimentally infected with Cryptosporidium isolated from calves. Am J Vet Res $1981 ; 42: 1400-4$. 